\title{
High temperature plastic deformation of CuZn30 brass - calculation of the activation energy
}

\author{
R. Pernis ${ }^{1 *}$, J. Kasala $^{1}$, J. Bořuta ${ }^{2}$ \\ ${ }^{1}$ Alexander Dubček University of Trenčín, Faculty of Special Technology, Studentská 1, 91150 Trenčín, Slovak Republic \\ ${ }^{2}$ Materials and Metallurgy Research Ltd., Pohraniční 693/31, 70602 Ostrava-Vitkovice, Czech Republic
}

Received 16 September 2009, received in revised form 26 October 2009, accepted 26 October 2009

\begin{abstract}
High temperature plastic deformation of CuZn30 brass was investigated in the temperature range between $650^{\circ} \mathrm{C}$ and $850^{\circ} \mathrm{C}$. Torsion tests were performed for experimental plan according to test array $5 \times 4$, i.e. five temperatures $650,700,750,800,850{ }^{\circ} \mathrm{C}$ and four speeds of torsion shear strain rate $0.5,2.5,12.5$, and $25 \mathrm{~s}^{-1}$. Mathematical model has been developed to predict high-temperature shear stress behaviour of CuZn30 brass. Explicit equation, which is a function of peak stress, temperature and shear strain rate, was used in the mathematical model. There are four constants in the equation; one of those is the activation energy which for CuZn30 brass reaches the value $Q=180.3 \mathrm{~kJ} \mathrm{~mol}^{-1}$.

Measured and calculated values of shear stress are shown in graphs in dependence on the value of deformation, where the temperature of deformation and the speed of deformation are the parameters for the particular curves. The predicted results are in accordance with the experimental curves stress-deformation that can be used to model the behaviour of hot extrusion pressing of CuZn30 brass.
\end{abstract}

K e y w or d s: brass CuZn30, torsion test, strain, flow stress, activation energy

\section{Introduction}

CuZn30 brass belongs to the alpha brasses. Due to its good cold plastic flow properties it is used in technologies of deep drawing. Brass cups are traditionally manufactured from rolled semi products. High amounts of material waste originate from the process of cutting from the strips, so recycling in metallurgical plants is necessary [1]. Manufacturers have been preparing projects that would launch the manufacture of cups by no-waste technology from CuZn30 brass bars. Input semi products were replaced from the strips manufactured by rolling with the brass bars manufactured by hot extrusion pressing. This change is connected with the transition to new technology in metallurgical plants. Hot extrusion pressing resulted to be critical operation in technological process of CuZn30 brass bars manufacture [2]. In general, alpha brasses have good cold forming properties. The brass with $30 \%$ zinc reaches the highest level of formability for cold forming [3]. When CuZn30 brass is subjected to hot forming, the brass has lower formability. Therefore, by applying hot working to this brass, forming becomes hard. Flow stress at extrusion pressing of CuZn30 brass significantly depends on temperature, shear strain rate and area ratio. It has been shown that alpha-beta brasses are characterized by excellent hot forming properties. They are not so adaptable to cold forming process and therefore cold formability reaches lower values [4]. It is caused by change in the hardness proportion of $\alpha$ - and $\beta$-phase. When $\alpha$-phase is cold formed, it has lower hardness than $\beta$-phase. On the other hand, when $\alpha$-phase is hot formed, it has higher hardness than $\beta$-phase. The tension test is the most common test to find out hot flow stress [5]. It is not sufficient for hot forming processes at higher shear strain rates. In the study of hot extrusion process of CuZn30 brass, it is necessary to know the value of the activation energy. Modelling of deformation process through torsion plastometer was used to find out the activation energy [6]. Course of stress in dependence on deformation is observed during hot torsion

*Corresponding author: tel.: +421 32 7400210; e-mail address: pernis@tnuni.sk 
Table 1. Chemical composition of CuZn30 brass for torsion tests

\begin{tabular}{lccccccccc}
\hline Element & $\mathrm{Cu}$ & $\mathrm{Pb}$ & $\mathrm{Sn}$ & $\mathrm{Fe}$ & $\mathrm{Ni}$ & $\mathrm{Mn}$ & $\mathrm{Al}$ & $\mathrm{Si}$ \\
Content $(\%)$ & 70.39 & 0.0004 & 0.0042 & 0.0232 & 0.0022 & 0.0003 & 0.0012 & 0.0002 \\
\hline Element & $\mathrm{As}$ & $\mathrm{Sb}$ & $\mathrm{Bi}$ & $\mathrm{Cr}$ & $\mathrm{Cd}$ & $\mathrm{Ag}$ & $\mathrm{P}$ & $\mathrm{Zn}$ \\
Content $(\%)$ & 0.0001 & 0.0031 & 0.0001 & 0.0001 & 0.0001 & 0.0001 & 0.0002 & balance \\
\hline
\end{tabular}

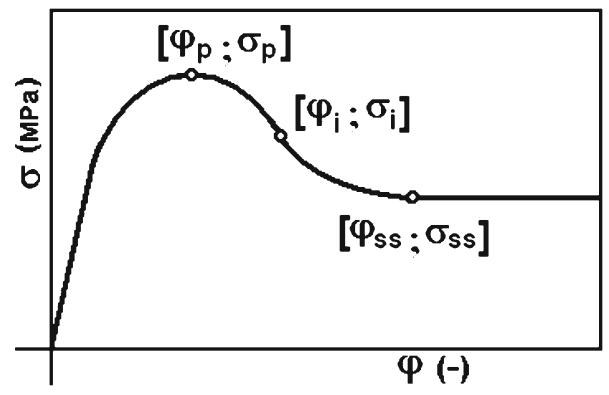

Fig. 1. Characteristic points on the curve stress vs. deformation.

test under defined conditions (geometry of specimen, temperature and shear strain rate). Figure 1 shows the characteristic course of the curve. The curve is characterized by several points marked on it. The curve where stress achieves the maximum value $\sigma_{\mathrm{p}}$ has coordinates $\left[\varphi_{\mathrm{p}} ; \sigma_{\mathrm{p}}\right]$. This stress is also known as peak stress $\sigma_{\mathrm{p}}$. Deformation at which the maximal stress is reached is $\varphi_{\mathrm{p}}$. Coordinates $\left[\varphi_{\mathrm{i}} ; \sigma_{\mathrm{i}}\right]$ characterize point of inflection. The beginning of steady state of deformation is characterized by coordinates $\left[\varphi_{\mathrm{ss}} ; \sigma_{\mathrm{ss}}\right]$, where index ss has its origin in English (steady state).

\section{Experimental procedure}

\subsection{Experimental material and experimental plan}

Deep drawing CuZn30 brass with chemical composition (see Table 1) was used for experimental hot torsion tests. Bars with diameter $10 \mathrm{~mm}$ [7] and [8] were used for the tests. Brass CuZn30 bars were manufactured according to the following technological process: melting in electric induction furnace, semi-continuous casting of billets, hot extrusion pressing and final cold drawing. The test specimens manufactured according to Fig. 2 were used for hot torsion tests.

Hot torsion tests of CuZn30 brass were performed according to the experimental plan consisting of the test array $5 \times 4$. That is five temperatures 650,700 , $750,800,850^{\circ} \mathrm{C}$ and four torsion shear strain rates 0.5 , $2.5,12.5$, and $25 \mathrm{~s}^{-1}$ that correspond to true speed of torsion 16, 80, 400, and $800 \mathrm{rpm}$.

\subsection{Mathematical formulas used in the evaluation of experimental results}

Mathematical relations applied in the evaluation of measured data of torsion test are listed in Table 2.

Basic deformation resistance was calculated from measured torque and axial force according to Eq. (1) (Table 2). The calculation of logarithmic deformation during torsion test was determined by Eq. (2) (Table 2). The value of torsion shear strain rate was calculated from Eq. (3) (Table 2). Mathematical description of hot deformation proceeding from Garafal empirical formula - Eq. (4) (Table 2) - for the description of high temperature deformation is stated by Drastík et al. [6]. In this equation, the activation energy is the parameter for the specific material. "Activation energy" is the most frequently used term in references; nevertheless, "the activation energy of plastic deformation" is a more precise term [9]. The material constants are determined on the basis of practically measured and calculated data.

\subsection{Experimental outcomes}

Torsion tests were performed in compliance with the experimental plan. The control computer was used to record immediate values: torque, axial force, temperature of specimen, speed of torsion and time baseline. Several ten thousands of data were gathered during the test; nevertheless, the question how to represent them emerged. Thereby, their visualization through graphs in coordinates of stress and deformation was chosen, while temperature and the speed of deformation are parameters. The results of torsion test for particular four values of torsion shear strain rates are in Figs. 3-6.

For particular temperatures, Fig. 7 shows curves of maximum values of peak stress $\sigma_{\mathrm{p}}$ in dependence on natural logarithm of torsion shear strain rate $\dot{\gamma}$.

\section{Results and discussion}

\subsection{Evaluation of measured data}

To describe the curves in Fig. 7, Eq. (4) (Table 2) was used. Material constants are determined by measured and calculated data. At first it is necessary to 
Ta b le 2. Mathematical relations applied in the evaluation of torsion test

\begin{tabular}{clcc}
\hline Equation number & Description & Symbols & Formulas \\
\hline$(1)$ & Basic deformation resistance & $\sigma_{\mathrm{ZDO}}$ & $\sigma_{\mathrm{ZDO}}=\sqrt{\left(\frac{3 \cdot \sqrt{3 \cdot M_{\mathrm{k}}}}{2 \pi \cdot R_{\mathrm{t}}^{3}}\right)^{2}\left(\frac{F}{\pi \cdot R_{\mathrm{t}}^{2}}\right)^{2}}$ \\
\hline$(2)$ & Logarithmic deformation & $\varphi$ & $\varphi=\frac{2}{\sqrt{3}} \operatorname{arcsinh}\left(\frac{2 \pi \cdot R_{\mathrm{t}} \cdot n_{\mathrm{s}}}{3 L}\right)$ \\
\hline$(3)$ & Torsion shear strain rate & $\dot{\gamma}$ & $\dot{\gamma}=\frac{2 \pi \cdot R_{\mathrm{t}}}{L} \cdot \frac{n_{\mathrm{r}}}{60}$ \\
\hline$(4)$ & $f\left(\sigma_{\mathrm{p}}, T, \dot{\gamma}\right)=0$ & - & $\dot{\gamma} \cdot \exp \left(\frac{Q}{R T}\right)=C \cdot\left[\sinh \left(\alpha \cdot \sigma_{\mathrm{p}}\right)\right]^{n}$ \\
\hline$(5)$ & Activation energy & $Q$ & $Q=k \cdot n \cdot R$ \\
\hline$(6)$ & Zener-Hollomon parameter & $Z$ & $Z=\dot{\gamma} \cdot \exp \left(\frac{Q}{R T}\right)$ \\
\hline
\end{tabular}

where

$M_{\mathrm{k}}-$ torque $(\mathrm{N} \mathrm{m})$

$F \quad-$ axial force $(\mathrm{N})$

$\sigma_{\mathrm{p}}-$ peak stress $(\mathrm{MPa})$

$R_{\mathrm{t}}-$ radius of test specimen $(\mathrm{mm})$

$L$ - length of test specimen ( $\mathrm{mm}$ )

$n_{\mathrm{r}} \quad-$ speed of torsion ( $\mathrm{rpm}$ )

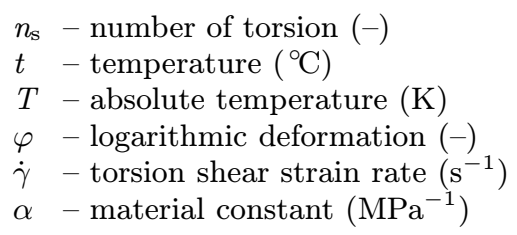

$n$ - material constant $(-)$

$Q$ - activation energy $\left(\mathrm{J} \mathrm{mol}^{-1}\right)$

$C$ - material constant $\left(\mathrm{s}^{-1}\right)$

$R$ - gas constant, $R=8.314 \mathrm{~J} \mathrm{~K}^{-1} \mathrm{~mol}^{-1}$

$k$ - slope of the line in coordinates $\ln \sinh \left(\alpha \cdot \sigma_{\mathrm{p}}\right)$ vs. $1 / T(\mathrm{~K})$

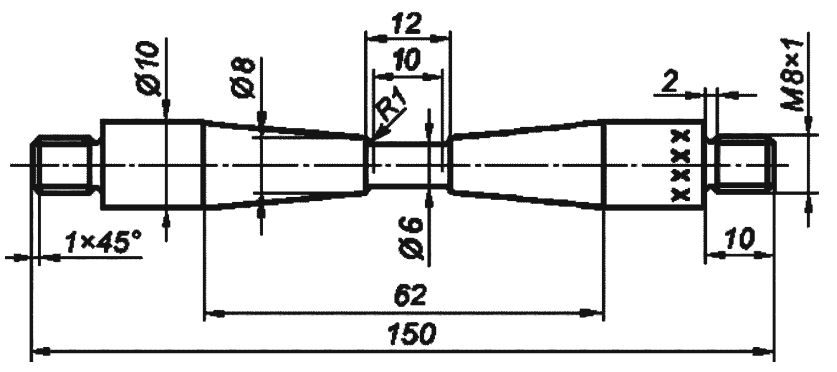

Fig. 2. Test specimen for hot torsion tests.

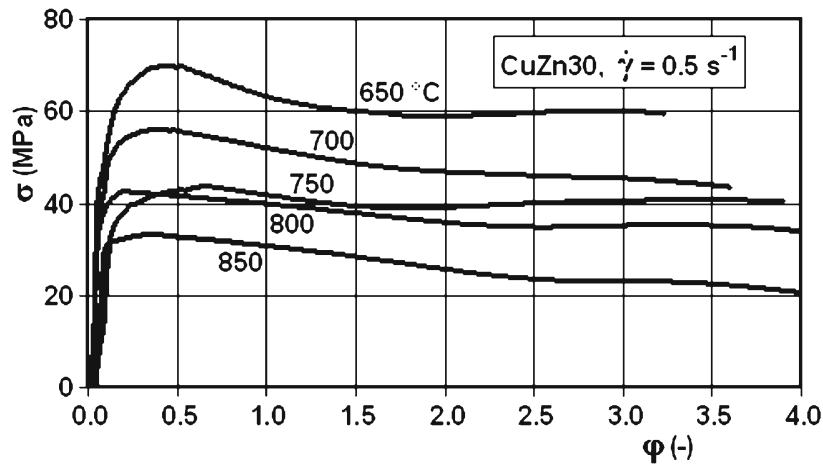

Fig. 3. Basic deformation resistance of CuZn30 brass for torsion shear strain rate $\dot{\gamma}=0.5 \mathrm{~s}^{-1}$.

specify the material constant $\alpha$ in order to determine remaining constants for Eq. (4) (Table 2). The

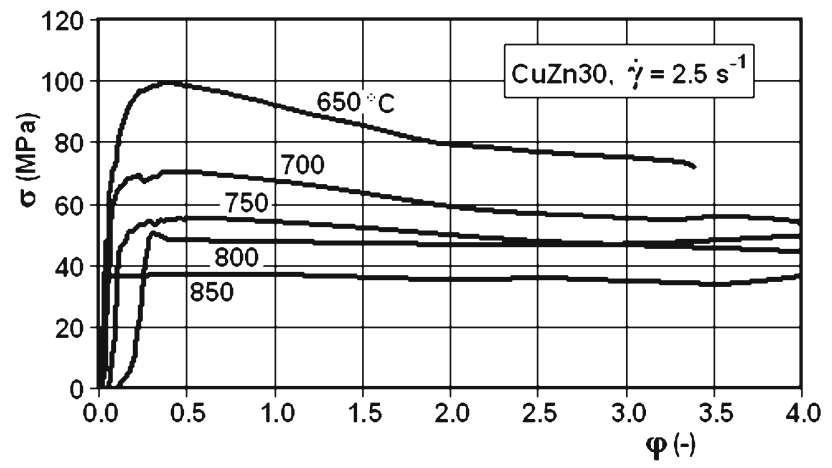

Fig. 4. Basic deformation resistance of CuZn30 brass for torsion shear strain rate $\dot{\gamma}=2.5 \mathrm{~s}^{-1}$.

determination of material constant was performed on the basis of procedure recommended in [6] and [1012]. Constant $\alpha=0.00927 \mathrm{MPa}^{-1}$ was calculated for hot deformation of CuZn30 brass.

To determine constant $n$ for Eq. (4) (Table 2), we need to linearize the equation. This can be achieved through the use of logarithmic scale on both axes. It requires displaying the scale on both axes where the temperature is parameter. This requirement can be ensured by the independent application of Eq. (4) (Table 2) for each measured temperature. For temperatures $650,700,750,800$, and $850^{\circ} \mathrm{C}$ we display five lines in logarithmic coordinates of $\ln \left(\sinh \left(\alpha \cdot \sigma_{\mathrm{p}}\right)\right)$ and $\ln \dot{\gamma}$. Line plots are shown in Fig. 8. 


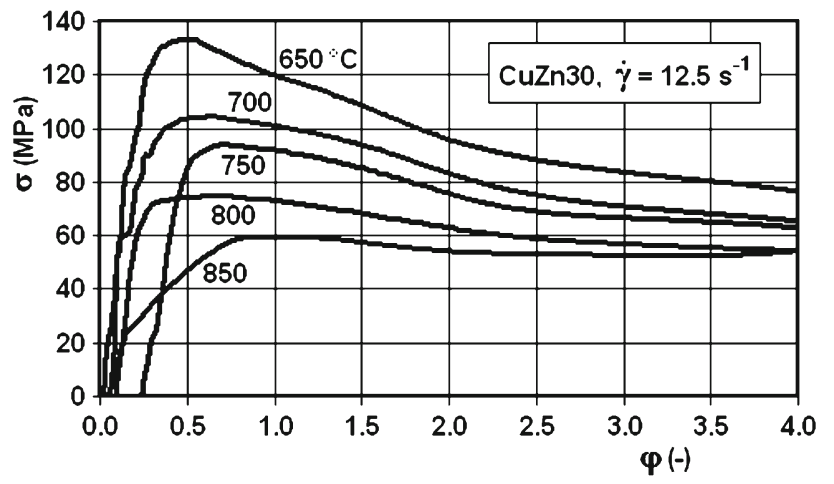

Fig. 5. Basic deformation resistance of CuZn30 brass for torsion shear strain rate $\dot{\gamma}=12.5 \mathrm{~s}^{-1}$.

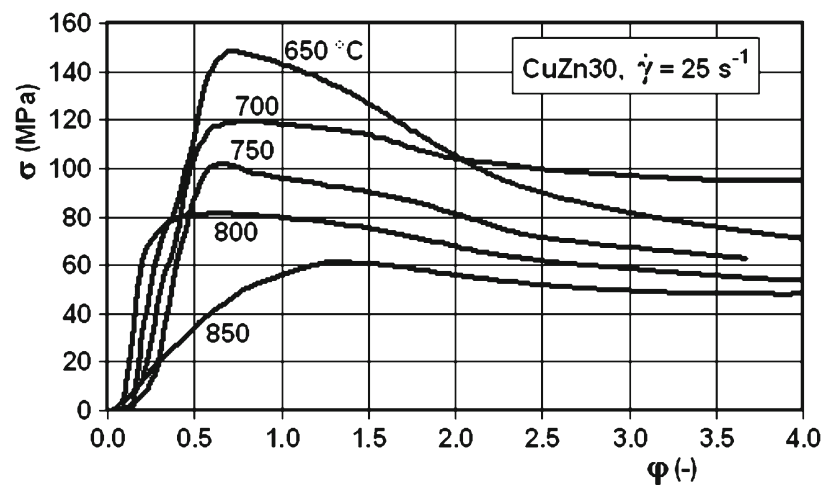

Fig. 6. Basic deformation resistance of CuZn30 brass for torsion shear strain rate $\dot{\gamma}=25 \mathrm{~s}^{-1}$.

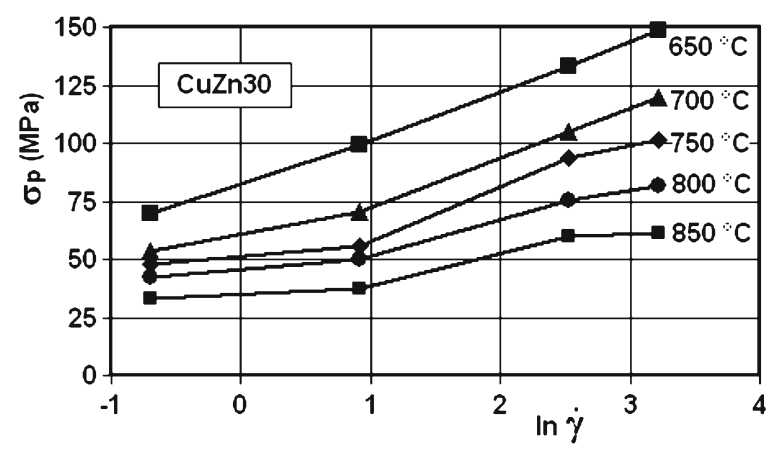

Fig. 7. Peak stress of CuZn30 brass in coordinates of $\sigma_{\mathrm{p}}$ and $\ln \dot{\gamma}$.

Parameter $n$ is represented by the slope of the line. Since five lines (for each temperature one) are displayed, the resulting constant $n$ was set as an average calculated from five values. The first estimation for constant $n$ is found to be 4.3679 .

The known value of constant $n$ enables us to determine the activation energy in the next step. The linearization of Eq. (4) (Table 2) is used likewise in

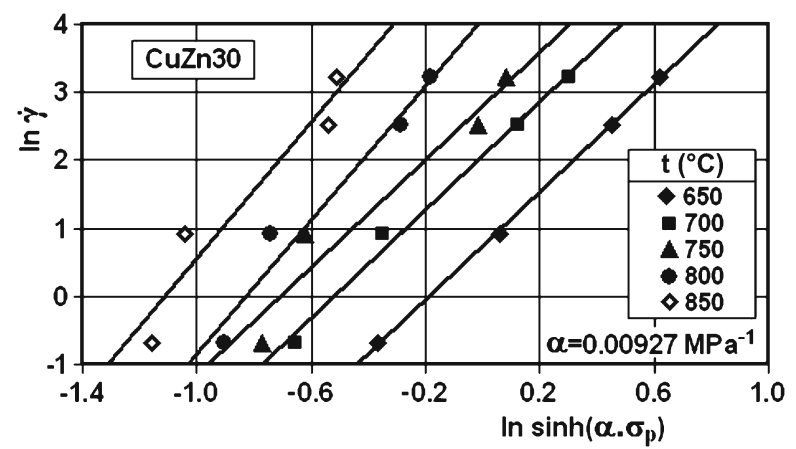

Fig. 8. Line plots at different temperatures determining material constant $n$.

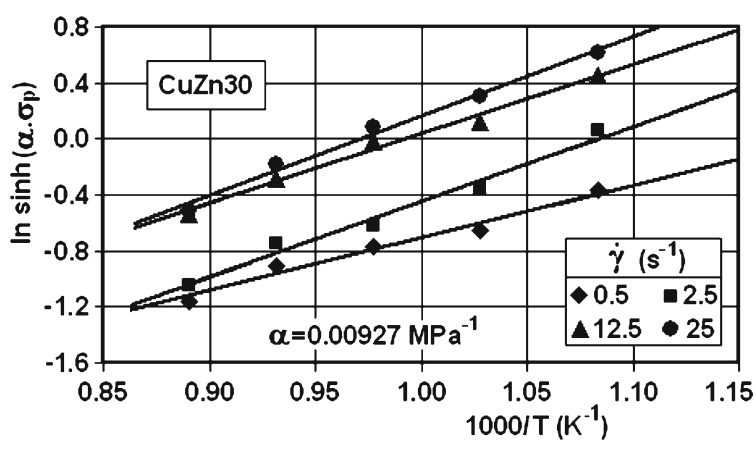

Fig. 9. Line plots describing the activation energy $Q$.

the process of the determination of the material constant $n$. Coordinate system $\ln \left(\sinh \left(\alpha \cdot \sigma_{\mathrm{p}}\right)\right)$ vs. $1 / T$ is used for measured values where the speed of deformation is the parameter [13]. Figure 9 shows line plots for the determination of the activation energy. The value of slope of the line $k$ was set as an average calculated from four values in Fig. 9. The final value of the activation energy for CuZn30 brass was calculated from Eq. (5) (Table 2). The calculated value of the activation energy reaches $Q=180346 \mathrm{~J} \mathrm{~mol}^{-1}$.

Constant $C$ is the last material constant of Eq. (4) (Table 2) describing high temperature deformation. The Zener-Hollomon parameter $Z$ [14] was used to determine $C$ (see Eq. (6) (Table 2)). Zener-Hollomon parameter $Z$ is determined from the known value of the activation energy. The specific values of natural logarithm of Zener-Hollomon parameter for high temperature deformation behaviour of CuZn30 brass are stated in Table 3.

The graph in coordinates of $\ln Z$ and $\ln (\sinh (\alpha$. $\left.\sigma_{\mathrm{p}}\right)$ ) shown in Fig. 10 was drawn up by using data from Table 3. The curve represents line which slope of the line indicates improved material constant $n=$ 4.2899. The slope of the line approximates to the value of an initially estimated material parameter according to Fig. 8 . 
Ta ble 3. Natural logarithm of Zener-Hollomon parameter

\begin{tabular}{|c|c|c|c|c|}
\hline $\begin{array}{c}t \\
\left({ }^{\circ} \mathrm{C}\right)\end{array}$ & $\begin{array}{c}\dot{\gamma} \\
\left(\mathrm{s}^{-1}\right)\end{array}$ & $\begin{array}{c}\sigma_{\mathrm{p}} \\
(\mathrm{MPa})\end{array}$ & $\begin{array}{c}x \\
\ln \left(\sinh \left(\alpha \cdot \sigma_{\mathrm{p}}\right)\right)\end{array}$ & $\stackrel{y}{\ln Z}$ \\
\hline 650 & 0.5 & 69.949 & -0.3646 & 22.8046 \\
\hline 650 & 2.5 & 99.580 & 0.0577 & 24.4141 \\
\hline 650 & 12.5 & 133.370 & 0.4545 & 26.0235 \\
\hline 650 & 25.0 & 148.815 & 0.6203 & 26.7166 \\
\hline 700 & 0.5 & 53.739 & -0.6563 & 21.5973 \\
\hline 700 & 2.5 & 70.687 & -0.3526 & 23.2068 \\
\hline 700 & 12.5 & 104.608 & 0.1208 & 24.8162 \\
\hline 700 & 25.0 & 119.576 & 0.2994 & 25.5093 \\
\hline 750 & 0.5 & 48.168 & -0.7737 & 20.5080 \\
\hline 750 & 2.5 & 55.563 & -0.6201 & 22.1174 \\
\hline 750 & 12.5 & 93.895 & -0.0161 & 23.7269 \\
\hline 750 & 25.0 & 101.605 & 0.0833 & 24.4200 \\
\hline 800 & 0.5 & 42.534 & -0.9053 & 19.5202 \\
\hline 800 & 2.5 & 49.683 & -0.7406 & 21.1296 \\
\hline 800 & 12.5 & 75.053 & -0.2838 & 22.7391 \\
\hline 800 & 25.0 & 81.654 & -0.1852 & 23.4322 \\
\hline 850 & 0.5 & 33.377 & -1.1576 & 18.6204 \\
\hline 850 & 2.5 & 37.258 & -1.0437 & 20.2298 \\
\hline 850 & 12.5 & 59.678 & -0.5420 & 21.8392 \\
\hline 850 & 25.0 & 61.211 & -0.5140 & 22.5324 \\
\hline
\end{tabular}

Ta ble 4. Material constants of Eq. (4) (Table 2), CuZn30 brass

\begin{tabular}{cccc}
\hline No. & Material constants & Units & Value \\
\hline 1 & $\alpha$ & $\mathrm{MPa}^{-1}$ & 0.00927 \\
2 & $n$ & - & 4.2899 \\
3 & $Q$ & $\mathrm{~J} \mathrm{~mol}^{-1}$ & 180346 \\
4 & $C$ & $\mathrm{~s}^{-1}$ & $3.21603 \times 10^{10}$ \\
\hline
\end{tabular}

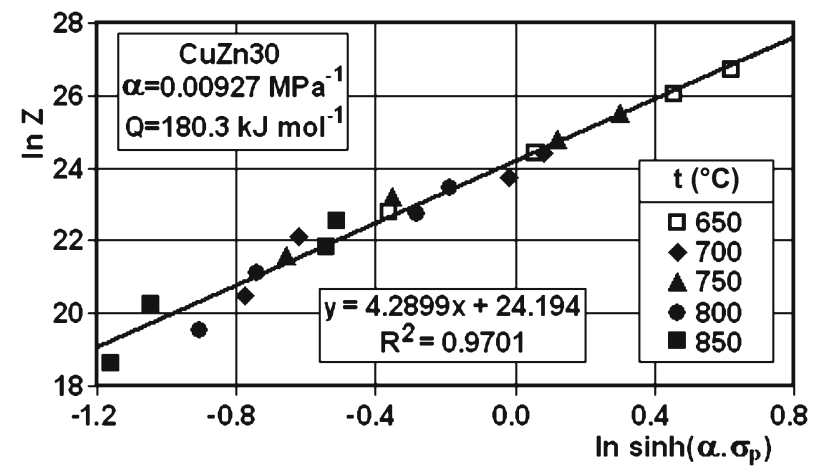

Fig. 10. Determination of constant $C$ by using Zener-Hollomon parameter.

Comparing these two values we get the difference $\Delta n=4.3679-4.2899=0.0780$. This difference originates from imperfect calculation procedure that was used for the first estimation of material parameter $n$ as an arithmetic average for particular temperatures. Segment on $y$-axis determines natural logarithm of constant $C$. Constant $C$ reaches the value 3.21603 $\times 10^{10} \mathrm{~s}^{-1}$. This process has been used to estimate the last and the fourth constant $C$ for Eq. (4) (Table 2), which describes high temperature deformation of CuZn30 brass. Calculated values of material parameters for Eq. (4) (Table 2) are shown in Table 4.

Particular equation describing high temperature deformation behaviour of CuZn30 brass was obtained by mathematical treatment of Eq. (4) (Table 2) and by using constants from Table 4 :

$\sigma_{\mathrm{p}}=107.87$

$\cdot \operatorname{arcsinh}\left\{\left[3.1095 \times 10^{-11} \cdot \dot{\gamma} \cdot \exp \left(\frac{21691}{T}\right)\right]^{0.2331}\right\}$.

The equation represents the peak stress as a function of temperature and strain rate. The stress can be considered to be the basic deformation resistance of hot extrusion pressing of CuZn30 brass.

\subsection{Discussion}

Experimentally measured data from torsion tests of CuZn30 brass and their evaluation confirmed the validity of Eq. (4) (Table 2) for the description of high temperature deformation behaviour. The proof is the 
plot of Zener-Hollomon parameter for the whole experimental range of temperatures and speeds given in Fig. 10, where tight correlation was achieved (correlation coefficient $R^{2}=0.97$ ).

Measured data shown in graphs in Figs. 3-6 confirmed that dynamic recrystallization and softening of deformed CuZn30 brass occur under certain conditions of deformation (logarithmic deformation, temperature and strain rate).

Achieved value of the activation energy enables us to examine relations of $\mathrm{CuZn} 30$ brass between conditions of deformation (strain rate, temperature of deformation) and microstructure (size of the grains) in the next studies.

Equation (A) enables us to calculate the basic deformation resistance of CuZn30 brass in dependence on temperature and strain rate. Equation $(\mathrm{A})$ is particularly suitable for the calculation of pressure force in extrusion pressing of brass CuZn30 bars.

\section{Conclusions}

Torsion test enabled us to verify suggested methods in forming, and their optimisation and simulation [15-17]. Experimental tests allowed us to get the basic deformation resistance under different conditions of deformation (temperature and strain rate). Further, torsion test enabled us to get and verify data about dynamic recovery, or dynamic recrystallization. Technological tests of hot extrusion pressing confirm ([18] and [19]) that CuZn30 brass has low formability, which is demonstrated in the occurrence of cross surface cracks. This was confirmed through model torsion tests under certain conditions. Peak stress, as the basic deformation resistance, enables us to calculate the force of hot extrusion pressing CuZn30 billets under working conditions.

\section{Acknowledgements}

The outcomes of the research of high temperature plastic deformations also served for the verification of innovation activities within the 5th phase of MSM 2587080701 MŠMT ČR project.

\section{References}

[1] PERNIS, R.: Acta Metallurgica Slovaca, 11, 2005, p. 351.

[2] ŠPÁNIK, J.-KROCHMAL, K.: Acta Metallurgica Slovaca, 13, 2007, p. 236.

[3] MAL'CEV, M. V.-BARSUKOVA, T. A.-BORIN, F. A.: Metalografia neželezných kovov a zliatin. Bratislava, SVTL 1963.

[4] ŽOLOBOV, V. V.-ZVEREV, G. I.: Pressovanie metallov. Moskva, Metallurgija 1971.

[5] BURŠÁK, M.-BACSÓ, J.: Skúšanie, kontrola a hodnotenie kvality materiálov. Košice, Emilena 2008.

[6] DRASTÍK, F.-ELFMARK, J. et al.: Plastometry a tvařitelnost kovů. Praha, SNTL 1977.

[7] PERNIS, R.-BOŘUTA, J.-BOŘUTA, A.: In: Transfer 2008: 10th International Scientific Conference. Eds.: Podmaková, E., Duudáková, R. Trenčín, Digital Graphic 2008, CD-ROM. p. 13.

[8] BOŘUTA, J.-GEMBALOVÁ, P.-OMACHT, D.BOŘUTA, A.-KUBÁNEK, Z.-KUBINA, T.SCHINDLER, I.: Hutnické listy, LXI, 2008, p. 80.

[9] BIDULSKÁ, J.-BIDULSKÝ, R.-CENIGA, L.KVAČKAJ, T.-CABIBBO, M.-EVANGELISTA, E.: Kovove Mater., 46, 2008, p. 151.

[10] KVAČKAJ, T.-POKORNY, I.-VLADO, M.: Acta Metallurgica Slovaca, 6, 2000, p. 242.

[11] SPIGARELLI, S.-CABIBBO, M.-EVANGELISTA, E.-BIDULSKÁ, J.: J. Mater. Sci., 38, 2003, p. 81.

[12] BIDULSKÁ, J.-KVAC̆KAJ, T.-BIDULSKÝ, R.CABIBBO, M.-EVANGELISTA, E.: Metallurgija, 46, 2007, p. 157 .

[13] GEMBALOVÁ, P.-BOŘUTA, J.-GRYCZ, E.CHMIEL, K. M.: Archives of Civil and Mechanical Engineering, VII, 2007, p. 21.

[14] SCHINDLER, I.-BOŘUTA, J.: Utilization Potentialities of the Torsion Plastometer. Katowice, Silesian Technical University 1998.

[15] GEMBALOVÁ P.-BOŘUTA J.-GRYCZ, E.SCHINDLER, I.: In: Steel Rolling 2006. Paris, ATS (L'Association Technique de la Sidérurgie) 2006, p. 17.

[16] GREGER, M.-KOCICH, R.-KUŘETOVÁ, B.: Grain refinement and superplasticity in magnesium alloys. In: NANO 2006. Brno, VUT Brno, p. 37.

[17] RUSZ, S.-DONIČ, T.-KLOS, M.: Acta Mechanica Slovaca, 10, 2006, p. 6.

[18] PERNIS, R.: In: Sborník IX. odborného semináře při konferenci IDET 2007 - Materiály a technologie ve výrobě speciální techniky. Brno, Univerzita obrany Brno 2007, p. 101.

[19] PERNIS, R.-HÍREŠ, O.-JURENOVÁ, J.: In: Metal 2007 - 16th International Conference on Metallurgy and Materials. Ostrava, Tanger s.r.o. 2007, p. 9. 